\title{
Precipitation Regime Shift Associated with the Pacific Decadal Oscillation in the Maritime Continent
}

\author{
V. Kokorev1,2, J. Ettema1, P. Siegmund2, G. van der Schrier² \\ ${ }^{1}$ Faculty of Geo-Information Science and Earth Observation, University of Twente, Enschede, The Netherlands \\ ${ }^{2}$ Royal Netherlands Meteorological Institute (KNMI), De Bilt, The Netherlands \\ Email: v.kokorev@utwente.nl
}

How to cite this paper: Kokorev, V., Ettema, J., Siegmund, P., \& van der Schrier, G. (2020). Precipitation Regime Shift Associated with the Pacific Decadal Oscillation in the Maritime Continent. American Journal of Climate Change, 9, 123-135. https://doi.org/10.4236/ajcc.2020.92009

Received: February 17, 2020

Accepted: June 5, 2020

Published: June 8, 2020

Copyright () 2020 by author(s) and Scientific Research Publishing Inc. This work is licensed under the Creative Commons Attribution International License (CC BY 4.0).

http://creativecommons.org/licenses/by/4.0/

\begin{abstract}
Recent changes in precipitation regime in South-East Asia are a subject of ongoing discussion. In this article, for the first time, evidence of a precipitation regime shift during the mid-1970s in the Northern Hemispheric part of South-East Asia is demonstrated. The detection of regime shifts is made possible by using a new comprehensive dataset of daily precipitation records (South-East Asian Climate Assessment and Dataset) and applying a novel Bayesian approach for regime shift detection. After the detected regime shift event in the mid-1970s, significant changes in precipitation distribution occurred in the Northern Hemispheric regions-Indochina Peninsula and the Philippines. More specifically, dry days became up to $10 \%$ more frequent in some regions. However, no precipitation regime shift is detected in Southern Hemisphere regions-Java and Northern Australia, were the number of observed dry days increased gradually.
\end{abstract}

\section{Keywords}

Regime Shift, Pacific Decadal Oscillation, Precipitation, South-East Asia, Bayesian Methods

\section{Introduction}

Precipitation extremes are changing worldwide (Bulygina, Razuvaev, Korshunova, \& Groisman, 2007; Groisman, Knight, \& Karl, 2012; O'Gorman, 2012) leading to increased drought frequencies. One of the affected regions is the Maritime continent, the part of South East Asia consisting of several archipelagos including Indonesia, Philippines, and Malaysia. South East Asia is highly vul- 
nerable to climate change effects (Hijioka et al., 2014). The air temperature changes in the Maritime Continent are well understood; in recent decades the number of cool days and cool nights has decreased, while hot days and hot nights increased (Klein Tank et al., 2006; Marjuki et al., 2016). Both daily maximum and minimum temperatures have increased significantly, with minimum temperatures increasing almost twice as fast (Marjuki et al., 2016; Supari, Tangang, Juneng, \& Aldrian, 2017). In contrast, precipitation changes are much less understood-the existing studies fail to identify statistically significant trends in the onset of the wet season or the length of the dry spells (Marjuki et al., 2016), or in precipitation extremes (Klein Tank et al., 2006), or found precipitation trends to be not significant and spatially coherent (Supari et al., 2017). The Intergovernmental Panel on Climate Change (IPCC) Fifth Assessment Report shows that in South-East Asia both the number and the quality of observations are insufficient for estimating current precipitation trends (Hijioka et al., 2014). That same report states that precipitation trends are highly variable, and both positive and negative trends have been observed. High variability and a lack of data mask trends and changes in distribution parameters, as well as large-scale regime shifts.

One of the main factors governing precipitation in South East Asia is the sea surface temperature (SST) (Hendon, 2003). Studying SST variability and trends can provide valuable insight into changes of precipitation regime. Long-period oceanic oscillations such as El Niño Southern Oscillation (ENSO), Pacific Decadal Oscillation (PDO), and Indian Ocean Dipole (IOD) have a significant effect on local SST (Kusuma et al., 2017) and, therefore, contribute to high variability of precipitation in the Maritime Continent. Changes in SST in the Maritime continent are well established in the satellite era but have high uncertainty in the period before (Merchant et al., 2019). In recent decades positive SST trends were observed, since 1950 to 2009 the surface temperatures of Indian ocean warmed by $0.65^{\circ} \mathrm{C}$, and the Pacific by $0.31^{\circ} \mathrm{C}$ (Hoegh-Guldberg et al., 2014); the Ocean Heat Content also demonstrate rapid warming in the same period (Cheng, Abraham, Hausfather, \& Trenberth, 2019). The PDO index shows 20 - 30 years cycles in SST in the Pacific, with rapid changes in SST during phase changes (Mantua \& Hare, 2002). There is an overwhelming amount of literature documenting environmental impact of PDO phase change (Hare \& Mantua, 2000; Mantua \& Hare, 2002; Newman et al., 2016). The best-known Pacific decadal oscillation phase change occurred in 1976, when a warm phase followed a cold phase causing an SST increase of about $0.5^{\circ} \mathrm{C}$. Since SST is a main driver of the precipitation regime in the Maritime Continent, a significant change in SST should lead to a measurable shift in precipitation. Precipitation regime shift around 1978 driven by PDO phase change observed and described by (Yang \& $\mathrm{Fu}, 2017)$ in China and USA. Our recent article suggests a mechanism of PDO-ENSO interactions causing precipitation regime shift in the Maritime Continent, but a quantitative evidence of observing such regime shift is lacking (Kokorev, Ettema, \& Siegmund, 2020). 
Here we focus on identifying and quantifying recent precipitation regime shifts and changes in the precipitation distribution in South East Asia. We apply a Bayesian approach to detect precipitation regime shifts, uncover changes in distribution parameters even if the mean is stationary. The proposed method provides uncertainty estimates for each detected regime shift event. The goal of this study is to apply Bayesian regime shift detection to state-of-the-art precipitation datasets, and thereby, bring about an improved understanding of recent changes in South East Asian precipitation regimes. Knowing regime shift points allows us to better estimate recent trends in precipitation and improves our understanding of modern climate changes in the Maritime Continent.

\section{Materials and Methods}

This study uses a Bayesian approach for detecting precipitation regime shifts, which was adopted from (Ó Ruanaidh \& Fitzgerald, 1996). A similar approach has been used in several studies (Chu \& Zhao, 2004; Ruggieri, 2013; Western \& Kleykamp, 2017). Simple example of the Python realization of this approach can be found in (Davidson-Pilon, 2015). The realization used in this study available at github.com/kokorev/prs. To the best of our knowledge this is the first study in which this method is adopted for precipitation regime shift detection.

To adopt the method for regime shift detection a distribution that describes daily precipitation data should be chosen. A literature review analyzing choice of statistical distribution in precipitation studies shows that Gamma distribution is most common choice for trends and climate change analysis (Ye, Hanson, Ding, Wang, \& Vogel, 2018). However, in this study, we want to consider a possible change in frequency of dry days which is not allowed by normal Gamma distribution and therefore we use a Zero Inflated Gamma distribution to describe observed daily precipitation data. This choice is motivated by ease of interpretation of the results due to having percent of zero precipitation days as an explicit parameter. The Zero Inflated Gamma distribution uses same base $\alpha$ and $\beta$ parameters as regular Gamma but adds an additional parameter $\pi$ describing a probability of zero rainfall. So, the resulting distribution has three parameters-a shape parameter $\alpha$, a rate or inverse scale parameter $\beta$, and probability of zero rainfall $\pi$. The specific implementation of the Zero Inflated Gamma in python code given in GitHub repository linked above. The daily rainfall $R$ is expressed as:

$$
R \sim \gamma(\alpha, \beta, \pi)
$$

where $\gamma$ is Zero Inflated Gamma distribution. After a regime shift at time $\tau$, at least one distribution parameter has changed significantly. Therefore, there is one set of parameters up to time $\tau$ and another set of parameters thereafter (2).

$$
\alpha, \beta, \pi= \begin{cases}\alpha_{1}, \beta_{1}, \pi_{1} & \text { if } t<\tau \\ \alpha_{2}, \beta_{2}, \pi_{2} & \text { if } t \geq \tau\end{cases}
$$


This Bayesian model has seven unknown parameters $\left(\alpha_{1}, \alpha_{2}, \beta_{1}, \beta_{2}, \pi_{1}, \pi_{2}, \tau\right)$ for which prior formulas are defined (Equations (3)-(6)). Prior values describe the situation in which there is no regime shift, and in which the distributions before and after the regime shift are equal: $\gamma\left(\alpha_{1}, \beta_{1}, \pi_{1}\right)=\gamma\left(\alpha_{2}, \beta_{2}, \pi_{2}\right)$. The priors for $\alpha$ and $\beta$ follow the normal distributions defined by mean value $\mu$ and standard deviation $\sigma$ (Equations (3) and (4)).

$$
\begin{gathered}
\alpha_{1}=\alpha_{2}=\operatorname{Normal}(\mu=1, \sigma=1.5) \\
\beta_{1}=\beta_{2}=\operatorname{Normal}(\mu=0.1, \sigma=0.5)
\end{gathered}
$$

The values of $\mu$ and $\sigma$ in equations were selected based on the mean values from observational data.

The prior probability of zero rainfall $\pi$ is uniformly distributed from zero to one (Equation (5)).

$$
\pi_{1}=\pi_{2}=\operatorname{Uniform}(\min =0, \max =1)
$$

Finally, the prior for regime shift defined as uniform distribution between all time steps, except for the first and final five years (Equation (6)). Excluding first and last few years from possibly having a regime shift is necessary to make sure that there is enough data for regime shift detection in period before and after the shift. According to Beaulieu et al. (2012), at least four year data are needed to detect regime shifts with a magnitude of one standard deviation. In this study we increase this minimal necessary period to 5 years to improve the robustness of regime shift detection.

$$
\tau=\operatorname{Uniform}\left(t_{0}+365 \times 5, t_{n}-365 \times 5\right)
$$

This approach can provide a robust quantification of a regime shift and the uncertainty of its position as well as of the distribution parameters before and after the regime shift.

\section{Sources of Data}

Lack of data is one of the main obstacles in understanding historical precipitation changes in South-East Asia. This study uses the South-East Asian Climate Assessment \& Dataset (SACA \& D, http://sacad.database.bmkg.go.id, Marjuki et al. 2016) (van den Besselaar, van der Schrier, Cornes, Iqbal, \& Klein Tank, 2017). SACA \& D is a state-of-the-art database covering Southeast Asia, specifically the ASEAN countries (Association of Southeast Asian Nations) and a part of WMO region $\mathrm{V}$. The database is specifically designed for climate monitoring and puts particular emphasis on changes in extremes. The daily data is acquired through cooperation with regional National Meteorological Services. At the time of writing (April 2019), SACA \& D receives data from 23 participants in 15 countries and the SACA dataset contains a total of 5926 series of observations. Full special extent of the dataset as well as distribution of stations by length of observation period shown on Figure 1. These series are obtained from 4066 meteorological stations. To our knowledge, this is the most comprehensive archive of observed 


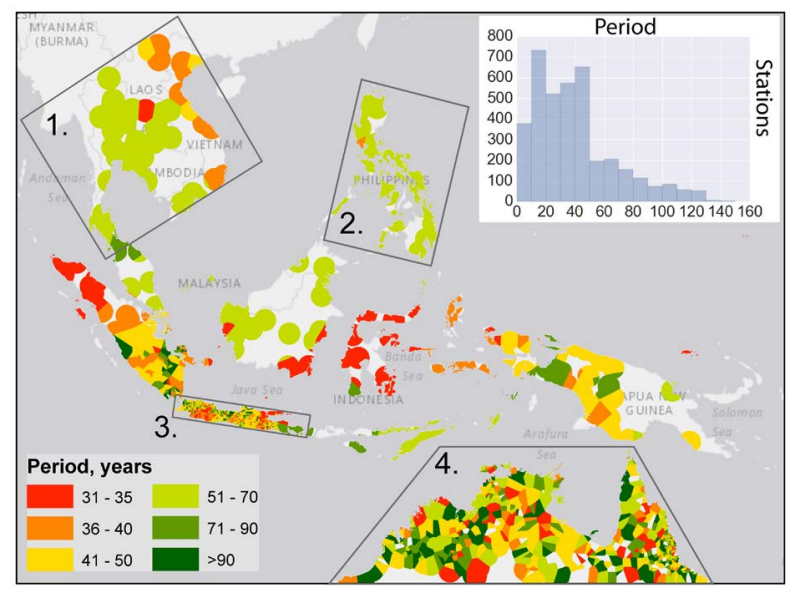

Figure 1. Map showing the duration of available time series at the closest weather station for stations $<50 \mathrm{~km}$ away. Stations with less than 30 years of data are not shown on the map. The inset histogram shows the distribution of stations by number of years with observations. The four areas with sufficient data density and duration are shown with dark gray boxes. 1-Indochina, 2-Philippines, 3-Java, 4-North Australia.

daily precipitation data currently available for this region. SACA \& D best estimates of grid square averages have been compared with station observations and other gridded station or satellite-based datasets, and their daily uncertainties have been quantified (van den Besselaar et al., 2017). In this study, we use only precipitation data; however, also other parameters are available in the dataset. Precipitation and extreme temperatures have the most comprehensive spatial and temporal coverage, but relative humidity, sunshine duration and wind parameters are also available.

The data used in this study have passed series of quality checks including sanity tests, homogeneity tests, consistency tests, and outlier tests. The test specifics are described in the Algorithm Theoretical Basis Document (ECA \& D Project Team, 2013) and only the data that passed all tests are used in this study. Long climatological observation records are often inhomogeneous as a result of station relocation, changes in methodology or changes in instrumentation (Aguilar, Auer, Brunet, Peterson, \& Wieringa, 2003). Within SACA \& D, series homogeneity is classified using the methods suggested by (Wijngaard, Klein Tank, \& Können, 2003). The procedure applies four tests: the Standard Normal Homogeneity Test (Alexandersson, 1986), the Buishand Range test (Buishand, 1982), the Pettitt test (Pettitt, 1979) and the Von Neumann Ratio test (von Neumann, 1941). Precipitation series are tested using the annual wet day count (using a threshold of $1 \mathrm{~mm}$ ). If the null-hypothesis of no break in the series is rejected by none or just one test, the series is classified as "useful"; if two tests reject the null-hypothesis, the series is classified as "doubtful" and if three or four tests reject the null-hypothesis, the label of "suspect" is given to the series (Marjuki et al. 2016).

Despite the high number of observations, insufficient coverage remains a critical problem for many regions due to the highly unequal spatial distributions of 
stations. For example, more than half of the stations (2885) are in Indonesia, of which the majority are located on the island of Java. Northern Australia accounts for another 1043 stations. Other countries have a much lower density of stations; for example, the Philippines has 37 stations followed by Thailand (30), Micronesia (28), Vietnam (15). The remaining nine stations are distributed between Papua New Guinea, Fiji, Samoa, the Solomon Islands, Kiribati, and Singapore.

Such an uneven spatial distribution does not allow statistics to be reliably calculated for the whole dataset, as the regions with higher number of stations would be disproportionally represented.

The durations of the available data series also vary significantly from region to region. Typically, 30 years is considered a minimal period for calculating climate reliable statistics (WMO, 2017). Even longer series are preferable for our study as we estimate climate parameters both before and after the regime shift. Therefore, in this study, we have only considered stations that have observational periods of at least 50 years. Figure 1 shows the length of the available data series per station, with each station represented by a Voronoi polygon cropped to a $100-\mathrm{km}$ radius around the station. Green indicate stations for which there are at least 50 years of data, while yellow and red indicate stations with insufficient data for this study.

Four regions satisfy the data requirement for this study and were selected for detailed analysis, namely the Indochina peninsula, the Philippines, the island of Java, and Northern Australia. The regions selected for analyses are shown in Figure 1.

Some of the long-period stations remain outside the selected regions and have not been analyzed. Analyzing separate stations could introduce random bias into the results, due to the high variability of the data. Having a spatially dense observation network reduces random errors by spatially averaging the results. For this reason, long-period stations in South Sumatra, Malaysia and Papua were not included in the analysis.

\section{Results and Discussions}

\subsection{Indochina}

The results from the Bayesian model show that Indochina is a region characterized by a clear and coherent precipitation regime shift. Most stations experienced a regime shift in 1974, with some outliers shifting the region mean to 1975. Figure 2 shows the timing of the regime shift at individual stations. Figure 2(a) the abscissa shows the regime shift date as an absolute anomaly, in years, from the regional mean regime shift date the ordinate shows the standard deviation of the regime shift date $\sigma(\tau)$ in years. The $\sigma(\tau)$ characterizes the confidence in the regime shift position. The figure shows that stations that have a regime shift date further from the regional mean have higher uncertainty in regime shift position. The darker the background color, the less chance there is of a station having its regime shift simultaneously with the regional mean. For 


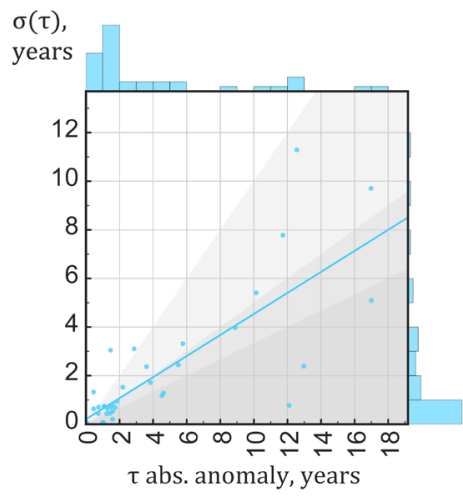

(a)

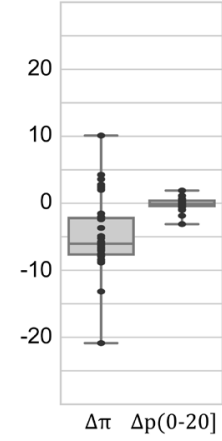

(b)

Figure 2. Precipitation regime shift in Indochina. (a) Date (absolute anomaly from regional mean) of regime shift versus standard deviation per station; (b) Changes in probability of no rainfall $(\Delta \pi)$ and probability of rainfall with intensity of $<20 \mathrm{~mm}$ per day $(\Delta \mathrm{p}(0$ - 20]). Black dots represent individual stations and boxes shows $25,50,75$ quantiles. Background colors indicate stations that have the regime shift date anomaly within one standard deviation from the regional mean (white), one to two standard deviations (light gray), two to three (gray), and greater than three (dark gray).

stations within two standard deviations (white or light grey), there is a significant chance that the actual regime shift occurred simultaneously with the regional mean. Figure 2(a) shows that almost all stations lie within two standard deviations of the mean regime shift date, meaning that there is a significant probability that the regime shift at those stations occurred at the same time as for most of the region. We confidently conclude that the regime shift in Indochina was observed around 1975. Only five stations exceed three standard deviations from the mean; two of those stations are in the Phetchabun mountains and the other three are in North Vietnam.

Figure 2(b) shows the changes in the probability distributions of no and $<20$ $\mathrm{mm}$ per day rainfall that occurred after the detected regime shift. The ordinate shows the change in probability of rainfall in percent, with the boxplot representing values for quantiles $25 \%, 50 \%, 75 \%$. For stations with a regime shift in 1974-75, the probability of a station having a dry day (no rainfall) decreased by $1 \%-9 \%$ after the shift. Outlier stations in the Phetchabun mountain region, with different regime shift dates, have a $2 \%-4 \%$ increase in the probability of having no rainfall. On average for the region, the probability of dry days decreased 5\% after the regime shift. For weak precipitation of an intensity above 0 but below $20 \mathrm{~mm}$ per day, the regional mean change is zero, but individual stations experienced small changes, typically $\pm 1 \%-2 \%$.

\subsection{Philippines}

In the Philippines, the regional mean regime shift occurred in 1975, similar to the Indochina region. However, unlike Indochina, there is more uncertainty in determining the precise timing of the regime shift. As seen in Figure 3, individual stations have much higher $\sigma(\tau)$ values compared to the Indochina region 


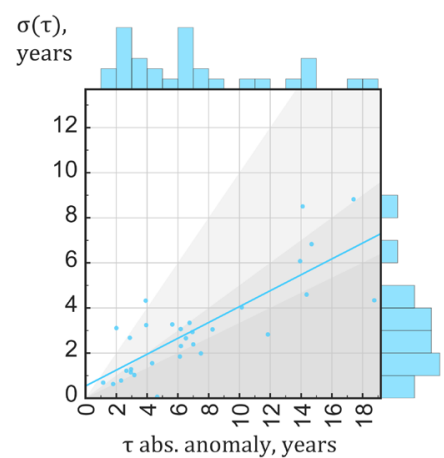

(a)

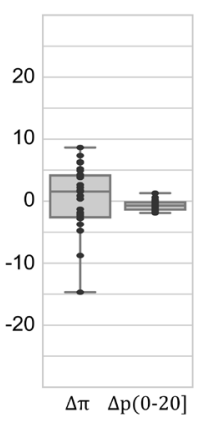

(b)

Figure 3. Precipitation regime shift in Philippines. (a) Date of regime shift versus standard deviation per station; (b) Changes in probability of no rainfall $(\Delta \pi)$ and probability of rainfall with intensity of $<20 \mathrm{~mm}$ per day $(\Delta \mathrm{p}(0-20])$. Black dots represent individual station and a box shows quantiles $25,50,75$. Background colors indicate stations that have the regime shift date anomaly within one standard deviation from the regional mean (white), one to two standard deviations (light gray), two to three (gray), and greater than three (dark gray).

and the regime shift timing varies significantly from station to station. Four stations with $\sigma(\tau) \leq 1$ year had tipping points in 1973, 1976, 1977, and 1980. Figure 3(a) shows that, similarly to Indochina region, stations at which the regime shift was detected further from 1975 have higher standard deviations of the regime shift position $\sigma(\tau)$. However, most stations were still within three standard deviations from the regional mean regime shift in 1975.

The magnitude of the regime shift, defined by difference in the distribution parameters before and after the regime shift, is similar in the Philippines and in the Indochina region, however, Philippines have much higher uncertainty in the regime shift position compared to Indochina. High uncertainty can mean that the transition between two regimes is smoother and occurred over several years making exact date of regime shift more difficult to establish and increasing uncertainty. If high uncertainty is caused by smooth transition between regimes and we assume that the regime shifts in Philippines and Indochina have the same trigger, we can expect that the mean regime shift date for the Philippines is the same as for Indochina which is confirmed by the data. Alternatively, high uncertainty can indicate lower observation quality, leading to inconclusive results. In complex terrain weather stations, often not representative of the surrounding region, variability between the stations is high. In such situations, much more data is needed to obtain conclusive results.

The spatial variability in the probability of no rainfall changes is high as well (Figure 3(b)). Values vary from $-10 \%$ to $+10 \%$, with the mean slightly above zero. The low confidence in the tipping point position does not explain the variability in the probability of no rainfall change. Values calculated from observed data, with the tipping point fixed at 1975, closely follow values from the posterior, e.g., a difference of less than $1 \%$ for the majority of stations. The probability of weak rainfall $(1-20 \mathrm{~mm}) \mathrm{mm} /$ day decreased $0 \%-3 \%$. 


\subsection{Java}

Java, unlike the other two previously examined regions, is located in the Southern Hemisphere, and no clear regime shift can be observed. The spatial and temporal variability in regime shift position is larger, and the regime shift distribution is much more uniform (Figure 4). Moreover, there is no correlation between the level of uncertainty and regime shift position, suggesting that there was no single regime shift year for the island of Java.

The magnitude of changes in precipitation distribution for Java is much higher than for the Indochina and Philippines. Large change together with no regime change point forms clear picture of steady linear trend toward drier climate in the observed period. The probability of a dry day increased $4 \%-6 \%$ for the majority of the stations and variations as high as $+10 \%$ are not uncommon. For weak precipitation with an intensity above zero but below $20 \mathrm{~mm}$, the median probability decreases around $2 \%$ but interregional variability is very high. Higher variability in all the parameters compared to Indochina and the Philippines is very characteristic for Java. While the majority of stations show significant changes toward a drier climate, a number of stations indicate the opposite. Stations with changes toward a drier climate often cluster together spatially, suggesting the influence of topography and sea currents.

\subsection{North Australia}

The North Australian region is similar to Java, no clear regime shift is observed, and many stations have a very high standard deviation of the regime shift position (Figure 5). This suggests that there was no regime shift in the Southern Hemisphere. This is consistent with the hypothesis of PDO influence causing precipitation regime shifts since PDO influence is observed primarily in Northern Hemisphere. The probability of no rainfall decreased slightly $(-2.5 \%)$ in the

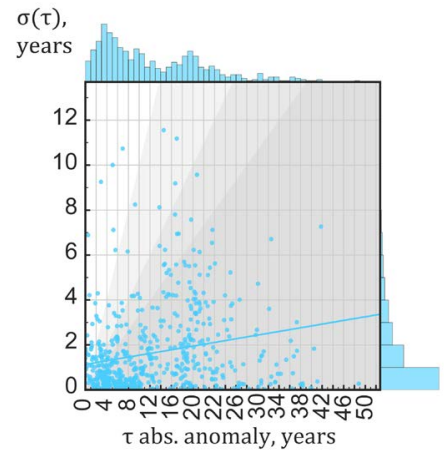

(a)

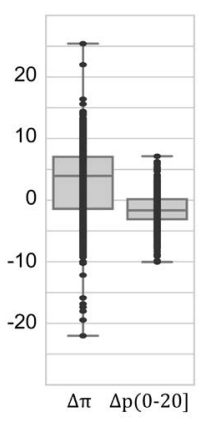

(b)

Figure 4. Precipitation regime shift in Java. (a) Date of regime shift versus standard deviation per station; (b) Changes in probability of no rainfall $(\Delta \pi)$ and probability of rainfall with intensity of $<20 \mathrm{~mm}$ per day $(\Delta \mathrm{p}(0-20])$. Black dots represent individual station and a box shows quantiles $25,50,75$. Background colors indicate stations that he the regime shift date anomaly within one standard deviation from the regional mean (white), one to two standard deviations (light gray), two to three (gray), and greater than three (dark gray). 


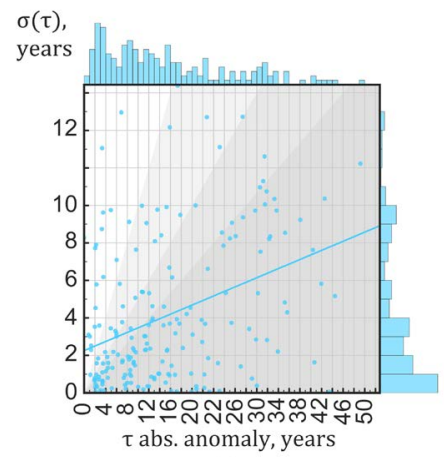

(a)

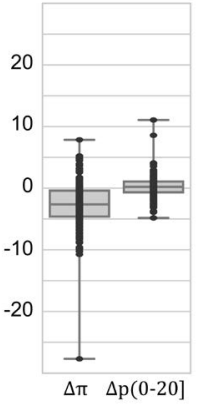

(b)

Figure 5. Precipitation regime shift in Australia. (a) Date of regime shift versus standard deviation per station; (b) Changes in probability of no rainfall $(\Delta \pi)$ and probability of rainfall with intensity of $<20 \mathrm{~mm}$ per day $(\Delta \mathrm{p}(0-20])$. Black dots represent individual station and a box shows quantiles $25,50,75$. Background colors indicate stations that have the regime shift date anomaly within one standard deviation from the regional mean (white), one to two standard deviations (light gray), two to three (gray), and greater than three (dark gray).

last 30 - 50 years. For precipitation of intensity above $0 \mathrm{~mm}$ and below $20 \mathrm{~mm}$, no changes were detected.

\section{Conclusion}

In this study, we used a Bayesian approach to quantify changes in precipitation regimes in four regions in South-East Asia. The precipitation changes in South-East Asia are a subject of a debate in literature. The presence of regime shift in Northern Hemisphere regions can explain the difficulty in detecting changes in precipitation regime in this region. Precipitation regime is stable for all but few years where regime shift occurs. High variability additionally masks the presence of a regime shift. Bayesian regime shift detection method allows to uncover underlaying changes and create a clear picture of changes that occurred.

The results demonstrate a significant increase in the prevalence of dry conditions in Java and a moderate increase in the number of days with precipitation in Indochina and the Philippines. The regime shift in the mid-1970s can be clearly observed in daily precipitation records for Indochina and Philippines. This agrees with the well-known change in the PDO phase in 1975/76. The physical connection between precipitation regime and PDO phase should be investigated further to predict future regime changes.

The presented Bayesian method for regime shift detection demonstrated good performance in detecting changes in daily precipitation records in South East Asia. While no change in the mean is present in many time series, the presented method is still capable of detecting a regime shift. Presented statistical method can be used for detecting regime shifts and tipping points in temperature, precipitation and other meteorological parameters. Additionally, presented method has a high potential in quality control applications and can be used for detecting data irregularities such as measuring equipment changes, station relocations. 


\section{Conflicts of Interest}

The authors declare no conflicts of interest regarding the publication of this paper.

\section{References}

Aguilar, E., Auer, I., Brunet, M., Peterson, T., \& Wieringa, J. (2003). Guidelines on Climate Metadata and Homogenization.

Alexandersson, H. (1986). A Homogeneity Test Applied to Precipitation Data. Journal of Climatology, 6, 661-675. https://doi.org/10.1002/joc.3370060607

Beaulieu, C., Chen, J., \& Sarmiento, J. L. (2012). Change-Point Analysis as a Tool to Detect Abrupt Climate Variations. Philosophical Transactions of The Royal Society $A$ Mathematical Physical and Engineering Sciences, 370, 1228-1249. https://doi.org/10.1098/rsta.2011.0383

Buishand, T. A. (1982). Some Methods for Testing the Homogeneity of Rainfall Records. Journal of Hydrology, 58, 11-27. https://doi.org/10.1016/0022-1694(82)90066-X

Bulygina, O. N., Razuvaev, V. N., Korshunova, N. N., \& Groisman, P. Y. (2007). Climate Variations and Changes in Extreme Climate Events in Russia. Environmental Research Letters, 2, Article No.: 045020. https://doi.org/10.1088/1748-9326/2/4/045020

Cheng, L., Abraham, J., Hausfather, Z., \& Trenberth, K. E. (2019). How Fast Are the Oceans Warming? Science, 363, 128-129. https://doi.org/10.1126/science.aav7619

Chu, P.-S., \& Zhao, X. (2004). Bayesian Change-Point Analysis of Tropical Cyclone Activity: The Central North Pacific Case. Journal of Climate, 17, 4893-4901. https://doi.org/10.1175/JCLI-3248.1

Davidson-Pilon, C. (2015). Bayesian Methods for Hackers: Probabilistic Programming and Bayesian Inference Using Python and PyMC. Boston, MA: Addison-Wesley Professional.

ECA \& D Project Team (2013). European Climate Assessment \& Dataset, Algorithm Theoretical Basis Document $(A T B D)$. Royal Netherlands Meteorological Institute KNMI. https://eca.knmi.nl/documents/atbd.pdf

Groisman, P. Y., Knight, R. W., \& Karl, T. R. (2012). Changes in Intense Precipitation over the Central United States. Journal of Hydrometeorology, 13, 47-66. https://doi.org/10.1175/JHM-D-11-039.1

Hare, S. R., \& Mantua, N. J. (2000). Empirical evidence for North Pacific regime shifts in 1977 and 1989. Progress in Oceanography, 47, 103-145. https://doi.org/10.1016/S0079-6611(00)00033-1

Hendon, H. H. (2003). Indonesian Rainfall Variability: Impacts of ENSO and Local Air-Sea Interaction. Journal of Climate, 16, 1775-1790. https://doi.org/10.1175/1520-0442(2003)016<1775:IRVIOE $>2.0 . C O ; 2$

Hijioka, Y., Lin, E., Pereira, J. J., Corlett, R. T., Cui, X., Insarov, G. E., et al. (2014). Asia. In V. R. Barros, C. B. Field, D. J. Dokken, M. D. Mastrandrea, K. J. Mach, T. E. Bilir, M. Chatterjee, K. L. Ebi, Y. O. Estrada, R. C. Genova, B. Girma, E. S. Kissel, A. N. Levy, S. MacCracken, P. R. Mastrandrea, \& L. L. White (Eds.), Climate Change 2014: Impacts, Adaptation, and Vulnerability. Part B: Regional Aspects. Contribution of Working Group II to the Fifth Assessment Report of the Intergovernmental Panel of Climate Change (pp. 1327-1370). Cambridge, UK and New York, NY: Cambridge University Press.

Hoegh-Guldberg, O., Cai, R., Poloczanska, E. S., Brewer, P. G., Sundby, S., Hilmi, K., et al. 
(2014). The Ocean. In V. R. Barros, C. B. Field, D. J. Dokken, M. D. Mastrandrea, K. J. Mach, T. E. Bilir, M. Chatterjee, K. L. Ebi, Y. O. Estrada, R. C. Genova, B. Girma, E. S. Kissel, A. N. Levy, S. MacCracken, P. R. Mastrandrea, \& L. L. White (Eds.), Climate Change 2014: Impacts, Adaptation, and Vulnerability. Part B: Regional Aspects. Contribution of Working Group II to the Fifth Assessment Report of the Intergovernmental Panel of Climate Change (pp. 1655-1731). Cambridge, UK and New York, NY: Cambridge University Press.

Klein Tank, A. M. G., Peterson, T. C., Quadir, D. A., Dorji, S., Zou, X., Tang, H., et al. (2006). Changes in Daily Temperature and Precipitation Extremes in Central and South Asia. Journal of Geophysical Research, 111, D16105. https://doi.org/10.1029/2005JD006316

Kokorev, V., Ettema, J., \& Siegmund, P. (2020). Analysis of PDO-ENSO Modulation Effect on Precipitation Anomalies in the Maritime Continent. International Journal of Climatology (in review).

Kusuma, W. D., Murdimanto, A., Y Aden, L., Sukresno, B., Jatisworo, D., \& Hanintyo, R. (2017). Sea Surface Temperature Dynamics in Indonesia. IOP Conference Series: Earth and Environmental Science, Volume 98, The 5th Geoinformation Science Symposium 2017 (GSS 2017), Yogyakarta, 27-28 September 2017. https://doi.org/10.1088/1755-1315/98/1/012038

Mantua, N. J., \& Hare, S. R. (2002). The Pacific Decadal Oscillation. Journal of Oceanography, 58, 35-44. https://doi.org/10.1023/A:1015820616384

Marjuki, van der Schrier, G., Klein Tank, A. M. G., van den Besselaar, E. J. M., Nurhayati, \& Swarinoto, Y. S. (2016). Observed Trends and Variability in Climate Indices Relevant for Crop Yields in Southeast Asia. Journal of Climate, 29, 2651-2669. https://doi.org/10.1175/JCLI-D-14-00574.1

Merchant, C. J., Embury, O., Bulgin, C. E., Block, T., Corlett, G. K., Fiedler, E., et al. (2019). Satellite-Based Time-Series of Sea-Surface Temperature since 1981 for Climate Applications. Scientific Data, 6, 223. https://doi.org/10.1038/s41597-019-0236-x

Newman, M., Alexander, M. A., Ault, T. R., Cobb, K. M., Deser, C., Di Lorenzo, E., et al. (2016). The Pacific Decadal Oscillation, Revisited. Journal of Climate, 29, 4399-4427. https://doi.org/10.1175/JCLI-D-15-0508.1

Ó Ruanaidh, J. J. K., \& Fitzgerald, W. J. (1996). Retrospective Changepoint Detection. In Numerical Bayesian Methods Applied to Signal Processing (pp. 96-121). New York, NY: Springer New York. https://doi.org/10.1007/978-1-4612-0717-7_5

O'Gorman, P. A. (2012). Sensitivity of Tropical Precipitation Extremes to Climate Change. Nature Geoscience, 5, 697-700. https://doi.org/10.1038/ngeo1568

Pettitt, A. N. (1979). A Non-Parametric Approach to the Change-Point Problem. Journal of the Royal Statistical Society. Series C (Applied Statistics), 28, 126-135. https://doi.org/10.2307/2346729

Ruggieri, E. (2013). A Bayesian Approach to Detecting Change Points in Climatic Records. International Journal of Climatology, 33, 520-528. https://doi.org/10.1002/joc.3447

Supari, Tangang, F., Juneng, L., \& Aldrian, E. (2017). Observed Changes in Extreme Temperature and Precipitation over Indonesia. International Journal of Climatology, 37, 1979-1997. https://doi.org/10.1002/joc.4829

van den Besselaar, E. J. M., van der Schrier, G., Cornes, R. C., Iqbal, A. S., \& Klein Tank, A. M. G. (2017). SA-OBS: A Daily Gridded Surface Temperature and Precipitation Dataset for Southeast Asia. Journal of Climate, 30, 5151-5165. 
https://doi.org/10.1175/JCLI-D-16-0575.1

von Neumann, J. (1941). Distribution of the Ratio of the Mean Square Successive Difference to the Variance. Annals of Mathematical Statistics, 12, 367-395. https://doi.org/10.1214/aoms/1177731677

Western, B., \& Kleykamp, M. (2017). A Bayesian Change Point Model for Historical Time Series Analysis. Political Analysis, 12, 354-374. https://doi.org/10.1093/pan/mph023

Wijngaard, J. B., Klein Tank, A. M. G., \& Können, G. P. (2003). Homogeneity of 20th Century European Daily Temperature and Precipitation Series. International Journal of Climatology, 23, 679-692. https://doi.org/10.1002/joc.906

WMO (2017). WMO Guidelines on the Calculation of Climate Normals.

Yang, L., \& Fu, Z. (2017). Out-Phased Decadal Precipitation Regime Shift in China and the United States. Theoretical and Applied Climatology, 130, 535-544.

https://doi.org/10.1007/s00704-016-1907-6

Ye, L., Hanson, L. S., Ding, P., Wang, D., \& Vogel, R. M. (2018). The Probability Distribution of Daily Precipitation at the Point and Catchment Scales in the United States. Hydrology and Earth System Sciences, 22, 6519-6531.

https://doi.org/10.5194/hess-22-6519-2018 